\title{
Dilated Cardiomyopathy at the Crossroad: Multidisciplinary Approach
}

\author{
Gianfranco Sinagra, Enrico Fabris, Simona Romani, \\ Francesco Negri, Davide Stolfo, Francesca Brun, \\ and Marco Merlo
}

\section{Abbreviations and Acronyms}

ACEi Angiotensin converting enzyme inhibitors

BMD Becker muscular dystrophy

BNP Brain natriuretic peptide

CK Creatine kinase

CMR Cardiac magnetic resonance

CS Cardiac sarcoidosis

DCM Dilated cardiomyopathy

DMD Duchenne muscular dystrophy

ECG Electrocardiogram

ECG-SA Signal-averaged electrocardiography

EDMD Emery-Dreifuss muscular dystrophy

HF Heart failure

LGMD Limb-girdle muscular dystrophy

LV Left ventricular

LVEF Left ventricular ejection fraction

NYHA New York Heart Association

SLE Systemic lupus erythematosus

TTNtv Truncation variants in the gene encoding titin

VT Ventricular tachycardia

\section{G. Sinagra $\cdot$ M. Merlo}

Cardiovascular Department, Azienda Sanitaria Universitaria Integrata, Trieste, Italy

e-mail: gianfranco.sinagra@asuits.sanita.fvg.it; marco.merlo@asuits.sanita.fvg.it

E. Fabris $(\bowtie) \cdot$ S. Romani $\cdot$ F. Negri $\cdot$ D. Stolfo $\cdot$ F. Brun

Cardiovascular Department, Azienda Sanitaria Universitaria Integrata, University of Trieste (ASUITS), Trieste, Italy

e-mail: davide.stolfo@ asuits.sanita.fvg.it; francesca.brun@ asuits.sanita.fvg.it

(C) The Author(s) 2019

G. Sinagra et al. (eds.), Dilated Cardiomyopathy,

https://doi.org/10.1007/978-3-030-13864-6_15 
Table 15.1 Clinical "red flags" and potential related DCM subgroup

\begin{tabular}{|c|c|c|c|}
\hline & Abnormalities & $\begin{array}{l}\text { Potential specific } \\
\text { DCM subgroup or } \\
\text { systemic disease }\end{array}$ & $\begin{array}{l}\text { Laboratory tests } \\
\text { suggested }\end{array}$ \\
\hline \multirow[t]{11}{*}{$\begin{array}{l}\text { Medical history/ } \\
\text { physical } \\
\text { examination }\end{array}$} & Mental retardation & $\begin{array}{l}\text { Dystrophinopathies, } \\
\text { Mitochondrial } \\
\text { diseases, } \\
\text { Myotonic dystrophy }\end{array}$ & Creatine kinase \\
\hline & Visual impairment & Myotonic dystrophy & Creatine kinase \\
\hline & Muscle weakness & $\begin{array}{l}\text { Desminopathy, } \\
\text { Dystrophinopathies, } \\
\text { Sarcoglycanopathies, } \\
\text { Laminopathies, } \\
\text { Myotonic dystrophy }\end{array}$ & Creatine kinase \\
\hline & Myotonia & Myotonic dystrophy & Creatine kinase \\
\hline & $\begin{array}{l}\text { Pigmentation of the } \\
\text { skin }\end{array}$ & Hemochromatosis & $\begin{array}{l}\text { Serum iron, ferritin, } \\
\text { transferrin saturation }\end{array}$ \\
\hline & $\begin{array}{l}\text { Uveitis; nodular } \\
\text { erythema; arthralgias }\end{array}$ & Sarcoidosis & $\begin{array}{l}\text { Serum angiotensin- } \\
\text { converting enzyme }\end{array}$ \\
\hline & $\begin{array}{l}\text { Malar rash, discoid } \\
\text { rash, oral ulcers, } \\
\text { arthritis, serositis; } \\
\text { fibrosis and thickening } \\
\text { of the skin }\end{array}$ & $\begin{array}{l}\text { Connective tissue } \\
\text { disorder (Systemic } \\
\text { lupus erythematosus, } \\
\text { scleroderma) }\end{array}$ & $\begin{array}{l}\text { Autoantibody screen, } \\
\text { erythrocyte } \\
\text { sedimentation rate, } \\
\text { proteinuria research }\end{array}$ \\
\hline & $\begin{array}{l}\text { Chemotherapy exposure } \\
\text { (anthracyclines, } \\
\text { trastuzumab, etc.) }\end{array}$ & $\begin{array}{l}\text { DCM related to } \\
\text { chemotherapeutic } \\
\text { agents }\end{array}$ & Troponin \\
\hline & $\begin{array}{l}\text { History of } \\
\text { amphetamines, cocaine } \\
\text { intake }\end{array}$ & $\begin{array}{l}\text { DCM related to toxic } \\
\text { agents }\end{array}$ & $\begin{array}{l}\text { Urine toxicology } \\
\text { screen for cocaine/ } \\
\text { amphetamine abuse }\end{array}$ \\
\hline & Alcohol abuse & Alcoholic DCM & $\begin{array}{l}\text { Liver function } \\
\text { Mean corpuscular } \\
\text { volume }\end{array}$ \\
\hline & Pregnancy & Peripartum-DCM & \\
\hline \multirow[t]{2}{*}{ Electrocardiography } & Atrioventricular block & $\begin{array}{l}\text { Myocarditis (Lyme } \\
\text { disease, Chagas } \\
\text { disease) } \\
\text { Sarcoidosis } \\
\text { Laminopathy } \\
\text { Desminopathy } \\
\text { Myotonic dystrophy } \\
\text { Emery-Dreifuss } 1\end{array}$ & $\begin{array}{l}\text { Specific serum } \\
\text { autoantibodies for } \\
\text { suspected infection: } \\
\text { Lyme disease, Chagas } \\
\text { disease, etc. } \\
\text { Serum angiotensin- } \\
\text { converting enzyme } \\
\text { (sarcoidosis) } \\
\text { Creatine kinase }\end{array}$ \\
\hline & $\begin{array}{l}\text { "Posterolateral } \\
\text { infarction" pattern }\end{array}$ & $\begin{array}{l}\text { Dystrophin-related } \\
\text { cardiomyopathy, } \\
\text { Limb-girdle } \\
\text { muscular dystrophy, } \\
\text { Sarcoidosis }\end{array}$ & $\begin{array}{l}\text { Creatine kinase, } \\
\text { Serum angiotensin- } \\
\text { converting enzyme } \\
\text { (sarcoidosis) }\end{array}$ \\
\hline \multirow[t]{2}{*}{ Echocardiography } & $\begin{array}{l}\text { Posterolateral akinesia/ } \\
\text { dyskinesia }\end{array}$ & $\begin{array}{l}\text { Dystrophin-related } \\
\text { cardiomyopathy }\end{array}$ & Creatine kinase \\
\hline & $\begin{array}{l}\text { Mild dilatation/segment } \\
\text { kinetic alterations with } \\
\text { non-coronary } \\
\text { distribution }\end{array}$ & $\begin{array}{l}\text { Myocarditis, } \\
\text { Sarcoidosis }\end{array}$ & $\begin{array}{l}\text { Troponin (myocarditis) } \\
\text { Serum angiotensin- } \\
\text { converting enzyme } \\
\text { (sarcoidosis) }\end{array}$ \\
\hline
\end{tabular}




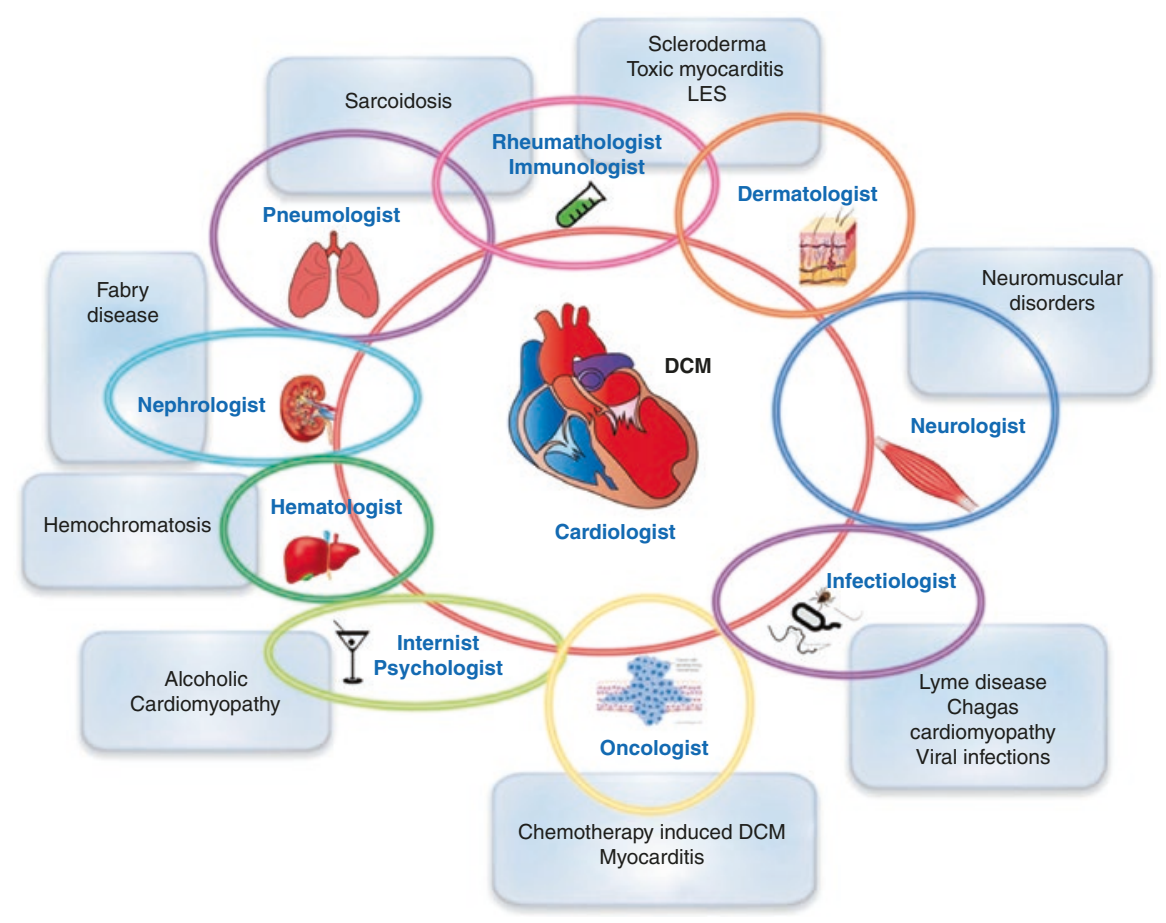

Fig. 15.1 Complex interactions between multiple specialties in the clinical management of DCM

Dilated cardiomyopathy (DCM) constitutes a broad cardiac phenotype that can arise from a multitude of myocardial insults. Rigorous etiological evaluation may allow to identify specific treatments, targeted to the underlying cause [1]. This approach requires clinical acumen (Table 15.1) and a multidisciplinary approach, with close collaboration with other specialists, as represented in Fig. 15.1.

Indeed, evaluation of patients with DCM requires a thorough understanding of potential complex pathophysiology that may be different in each patient [2]. In certain cases, with the elimination of the cause and the appropriate treatment, reversal of myocardial damage and recovery of cardiac dysfunction can occur, and therefore treatment should be individualized and should target the underlying cause, when added to the standard systolic heart failure (HF) therapies.

\subsection{Sarcoidosis: Co-working with Pneumologists}

Sarcoidosis is a systemic disease, characterized by noncaseating granuloma formation in multiple organ systems. The lung is the most frequently involved organ, and symptomatic patients have usually dry cough and dyspnea. Red flag of the disease is a bilateral lymphadenopathy at chest X-ray that is abnormal in about $90 \%$ of patients with pulmonary sarcoidosis [3]. In acute forms the multi-organ involvement suggests the diagnosis (uveitis, nodular erythema, arthralgia, etc.). Clinically 
manifest cardiac involvement occurs in about 5\% of patients with sarcoidosis [4]. The diagnosis of cardiac sarcoidosis (CS) requires appropriate clinical suspicion and the integration of clinical and pathologic data together with the results of advanced cardiac imaging techniques.

See Chap. 4 for diagnosis of sarcoidosis.

\subsubsection{Treatment}

The management of CS often requires multidisciplinary care teams. Indeed, electrophysiologists, heart failure specialists, imaging experts, pneumologists, and rheumatologists (especially when other organ involvement is present and when "biologic therapy" is required) have to work together to provide optimal patient management. Systemic corticosteroids remain the first-line treatment for sarcoidosis followed, if ineffective, by methotrexate. In patients with ventricular tachycardia (VT), refractory to immunosuppressive therapy, a first-line treatment is with antiarrhythmic drugs; then, if VT still persists, a catheter ablation is indicated (class IIa) [5]. Implantable cardioverter-defibrillator is indicated, over the conventional indication, if a patient with CS (independently of ventricular function) has an indication for permanent pacemaker implantation and presents unexplained syncope or nearsyncope and/or inducible sustained ventricular arrhythmias (class IIa) [5]. Many aspects of CS management, however, are not still fully understood, and further studies are needed for a better comprehension of the pathology, adequate risk stratification, treatment, and targeted follow-up.

\subsection{Autoimmune Cardiomyopathy: Co-working with Rheumatologists}

\subsubsection{Systemic Lupus Erythematosus}

Autoimmune diseases may be rare causes of cardiomyopathy and heart failure, mediated by several potential mechanisms, including immune-mediated myocarditis, progressive fibrosis, and apoptosis with resultant dilated phenotype.

The association between autoimmune disorders and DCM includes various autoimmune diseases, as the systemic lupus erythematosus (SLE) but also dermatomyositis, scleroderma, rheumatoid arthritis, and polyarteritis nodosa [2].

DCM is not a prominent manifestation of SLE; however myocardial involvement is not uncommon in the disease. At echocardiographic studies about $6 \%$ of SLE patients showed global hypokinesia [6], and evidence of myocarditis can be found at postmortem examination in approximately $40 \%$ of cases [7]. According to guidelines [8], the diagnosis of SLE can be made by a combination of clinical features and laboratory tests. Immunological tests should be investigated by cardiologists especially in a young woman with unexplained left ventricular dysfunction associated with clinical symptoms suggestive of autoimmune disorder (fatigue, fever, 
associated with skin, musculoskeletal, and mild hematologic disorders). Among immunological tests, antinuclear antibodies are present in 95\% of SLE patients. This test however has a high sensitivity but a low specificity [9].

Cardiovascular manifestations of SLE are heterogeneous and, in addition to pericarditis and less often myocarditis, may include also coronary artery disease, conduction system disease, valvular disease, and pulmonary hypertension in various associations [9]. Particularly, 12-lead ECG abnormalities include non-specific ST-T changes, left ventricular (LV) hypertrophy, and supraventricular/ventricular arrhythmias [10]. Signal-averaged electrocardiography (ECG-SA) is currently used for recording ventricular late potentials which are the expression of slowed and disorganized conduction through zones of myocardial scarring. Left ventricular diastolic dysfunction has been documented both in active and quiescent SLE patients. Active chronic myocarditis can be detected using cardiac magnetic resonance (CMR).

\subsubsection{Treatment}

Main drugs for disease treatment are corticosteroids and hydroxychloroquine in mild disease; in moderate and severe disease, other immunosuppressive drugs (e.g., methotrexate, cyclosporine, azathioprine, etc.) have to be added [8].

\subsection{Infectious Disease and Cardiomyopathy: Co-working with Infectious Disease Specialist}

\subsubsection{Chagas Cardiomyopathy}

Chagas disease is caused by the protozoan parasite Trypanosoma cruzi, which is transmitted by large, blood-sucking reduviid bugs of the subfamily Triatominae. This illness was originally confined to poor, rural areas of South and Central America; however in recent years, the disease is also spreading in the USA, Canada, and Europe due to the influx of immigrants from endemic countries [11]. The chronic cardiac involvement manifests as Chagas cardiomyopathy, characterized by a chronic myocarditis that involves all cardiac chambers and damage to the conduction system [12].

The myocardium damage is generally a progressive process that can be classified into stages: those with a normal ECG are considered to have the indeterminate phase of the disease (stage A). The appearance of ECG abnormalities implies disease progression (stage B) and precedes the appearance of symptoms of heart failure (stages $C$ and D) [13]. The most common initial signs are left anterior fascicular block, right bundle branch block, and segmental left ventricular wall motion abnormalities (the segments frequently involved are the infero-lateral wall and the apex). Late manifestations include sinus node dysfunction leading to severe bradycardia, high-degree atrioventricular blocks, non-sustained or sustained ventricular tachycardia, progressive dilated cardiomyopathy with congestive heart failure, apical aneurysms (usually of the left ventricle), and emboli [11]. 
The diagnosis of chronic infection relies on serological testing, through detection of IgG antibodies against $T$. cruzi. Cardiac involvement should be evaluated through ECG and echocardiography. A direct relationship exists between the number of alterations identified in a single ECG and the severity of myocardial damage. Holter monitoring, exercise stress testing, and cardiac MRI (CMR) should be considered in symptomatic patients [11]. New York Heart Association (NYHA) functional class, left ventricular systolic function, cardiomegaly, and non-sustained ventricular tachycardia have been consistently identified as important prognostic markers [14].

\subsubsection{Treatment}

The treatment of Chagas cardiomyopathy involves both parasite-specific therapy and adjunctive therapy for the management of heart failure. Treatment with antitrypanosomal drugs, benznidazole or nifurtimox, is generally offered to patients with chronic disease in the indeterminate phase and patients with mild to moderate disease. Sudden death is the main cause of death, followed by refractory heart failure and thromboembolism [11]. Although both amiodarone and implantable cardioverter-defibrillator have been used, data for these patients are scarce.

\subsubsection{Lyme Disease}

Lyme disease is a spirochetal infection, which is transmitted by the bite of infected Ixodes spp. ticks. In most cases, it is caused by Borrelia burgdorferi. The disease is diffused especially in wooded areas. Cardiac involvement occurs during the early disseminated phase of the disease. B. burgdorferi can affect all layers of the heart, causing a transmural inflammation, with a predominance of macrophage and lymphocytes. Moreover, vasculitis of the small and large intramyocardial vessel can occur [15].

The cardiac manifestations are usually coincident with other symptoms of the disease (erythema, arthritis, or neurologic disease); however, in rare cases, there is an exclusive cardiac involvement. The principal manifestation of Lyme carditis is self-limited alteration of the conduction system and commonly varying degrees of atrioventricular block. Less frequently pericarditis, endocarditis, myocarditis, pericardial effusion, myocardial infarction, coronary artery aneurysm, QT interval prolongation, tachyarrhythmias, and congestive heart failure have been reported [15]. Lyme myopericarditis is often self-limiting and mild. However, occasionally patients can develop symptomatic myocarditis with cardiac dysfunction [15]. Lardieri et al. reported two cases of patients affected by DCM in which B. burgdorferi was grown in the culture of myocardial biopsies. Cardiac function returned to normal following treatment with penicillin, in addition to standard heart failure therapy [16].

The diagnosis of Lyme carditis is challenging and requires the confirmation of the association between historical, clinical, and laboratory data. The disease is diagnosed 
most easily when the cardiac involvement presents in association with a history of thick bite and classical Lyme manifestations (erythema migrans, arthritis), in the setting of positive serologic testing for B. burgdorferi antibodies [15]. Echocardiography may provide evidence of myocardial dysfunction. Cardiac MRI plays a supportive role, typically displaying non-specific epicardial contrast enhancement [17].

\subsubsection{Treatment}

Antibiotic therapy in the early stages of the disease prevents or attenuates later complications. Patients who have minor cardiac involvement (PR interval less than $300 \mathrm{~ms}$ ) and no other symptoms should receive oral antibiotics, amoxicillin or doxycycline. Patients who have more severe cardiac involvement, such as second- or third-degree atrioventricular block or congestive heart failure, should be hospitalized and treated with intravenous ceftriaxone or high-dose penicillin G. Complete atrioventricular block usually resolves within 1 week, while minor conduction disturbances regress in 6 weeks [15].

\subsection{Dilated Cardiomyopathy Associated with Neuromuscular Diseases: Co-working with Neurologists}

Neuromuscular diseases encompass a broad spectrum of diagnoses with overlapping but distinct phenotypes [18], and most forms of cardiac involvement are detected from childhood to the second decade of life, but others can remain asymptomatic until later in life [18].

DCM occurs in a variety of inherited neuromuscular disorders and represents the interface between the cardiology and neurology specialties. Patients with DCM should undergo a comprehensive examination which includes a neuromuscular examination in order to detect potential neuromuscular disorders. Moreover, serum creatine kinase $(\mathrm{CK})$ dosage is useful during the diagnostic work-up of DCM with potential skeletal muscle involvement (see Table 15.1).

- X-linked recessive muscular dystrophies include Duchenne muscular dystrophy (DMD) with a more severe phenotype and Becker muscular dystrophy (BMD) with milder and more variable phenotype. These are caused by mutations within the dystrophin gene, located on the $\mathrm{X}$ chromosome. Physical exam can reveal calf pseudohypertrophy, shortening of the Achilles tendons and hyporeflexia or areflexia in weak muscles, lumbar lordosis which compensates for gluteal weakness, and the classic Gower's sign (the use of the hands and arms to "walk" up the own body from a squatting position due to lack of hip and thigh muscle strength). The incidence of cardiomyopathy in DMD increases with age. Although it is estimated that $25 \%$ of boys have cardiomyopathy at 6 years of age and $59 \%$ by 10 years of age, cardiac involvement is nearly ubiquitous in older patients with DMD, as 
more than $80 \%$ of young men over 18 years of age demonstrate evidence of cardiac dysfunction $[19,20]$. Cardiac involvement leads to a progressive decline in cardiac function with age, resulting in ventricular dysfunction that contributes to early death for heart failure. DMD causes a primary cardiomyopathy characterized by extensive fibrosis of postero-basal left ventricular wall, resulting in the characteristic electrocardiographic change of tall right precordial $\mathrm{R}$ waves and deep Q waves in leads I, aVL, and V5-6. Clinical cardiologist should be aware of this "red flag" which may orient to a dystrophin-related cardiomyopathy. Currently, clinical guidelines recommend the initial cardiac screening at the time of diagnosis of DMD, every 2 years until 10 years of age and then yearly thereafter. It seems that angiotensin converting enzyme inhibitors (ACEi) and betablockers may delay the onset and the progression of cardiac dysfunction and have to be recommended earlier in this disease and should become the mainstay of treatment of dystrophinopathic cardiomyopathy [21, 22].

- Emery-Dreifuss muscular dystrophy (EDMD) is a genetically heterogeneous disorder that can be inherited as an X-linked recessive, autosomal dominant or autosomal recessive disorder. The disease is generally characterized by progressive muscle wasting and weakness with typically early contractures of the elbows, Achilles tendons, and spine. DCM is seen in most patients with EDMD with common association of atrioventricular defects; however there is no correlation between the degree of neuromuscular involvement and the severity of cardiac abnormalities. Arrhythmogenic dilated cardiomyopathy and ventricular tachyarrhythmias are more common in autosomal dominant form (due to lamin A/C mutations).

- Limb-girdle muscular dystrophy (LGMD) is still used as a generic term to describe those patients with muscular dystrophy of girdle distribution. Indeed, it is characterized by proximal weakness affecting the pelvic and shoulder girdles. There is broad clinical heterogeneity among the various LGMDs, and cardiac involvement is very common in lamin $\mathrm{A} / \mathrm{C}$ mutation, which presents arrhythmias and conduction abnormalities and sarcoglycan disease which frequently presents a DCM phenotype.

- Myotonic muscular dystrophies, type 1 and type 2, are characterized by myotonia, seen as an impaired relaxation after muscle contraction. Myotonic dystrophy is a multisystemic disease and can be associated with DCM [23-26]. Cardiac manifestations include also atrioventricular block with occasional progression to complete heat block, atrial fibrillation, ventricular tachyarrhythmias, and reduced left ventricular ejection fraction.

\subsection{Primary Iron-Overload Cardiomyopathy: Co-working with the Hematologists}

Iron-overload cardiomyopathy can result from a primary disorder of iron metabolism or from secondary causes of iron overload, such as hematologic disorders. Hereditary hemochromatosis is commonly due to mutations in the HFE gene, an autosomal recessive disorder in which there is increased intestinal iron absorption. Cardiac hemochromatosis is an important and potentially preventable cause of heart 
failure [27]. This is initially characterized by diastolic dysfunction and conduction disturbances and in later stages by DCM. When evaluating a new cardiomyopathy, screening for iron overload should include serum ferritin and transferrin saturation. Cardiac involvement in hemochromatosis can often be diagnosed on the basis of history, clinical examination, laboratory testing, and noninvasive imaging. Myocardial iron overload can be detected also by CMR.

Current treatment modalities to remove excess iron stores include therapeutic phlebotomy and iron-chelating agents; congestive heart failure should be treated with standard heart failure treatment regimens. Timely diagnosis and treatment can prevent and in some cases reverse left ventricular dysfunction.

\subsection{Cardiomyopathy Related to Chemotherapeutic Agents: Co-working with Oncologists}

Cancer patients receiving chemotherapy have an increased risk of developing cardiovascular complications. Cardiotoxicity is one of the most concerning of these complications and is defined as a left ventricular ejection fraction (LVEF) decline of $\geq 5$ to $<55 \%$ with heart failure symptoms or an asymptomatic decrease of LVEF $\geq 10$ to $<55 \%$ during cancer therapy $[2,28]$.

Two different patterns of cytotoxicity have been recognized:

- Type I refers to the effects of the drugs that determine acute myocyte injury, causing irreversible damage and depressed cardiac function on a dose-dependent basis. The most commonly accepted pathophysiological mechanism of cardiotoxicity is oxidative damage: these molecules form complexes with iron causing free radicals production [29]. Anthracyclines are the prototype for this category. The cardiac damage is dose-dependent; for this reason, in an attempt to reduce this injury, the initial dose, which is recommended not to be exceeded, is usually the one that has shown to cause less than $5 \%$ of heart failure cases. In comparison with other cardiomyopathies, anthracycline cardiotoxicity appears to have a substantially worse prognosis, with mortality rates up to $60 \%$ at 2 years. The hazard ratio for mortality has been reported as being over threefold that of idiopathic dilated cardiomyopathy [30]. For this reason, cardiac-sparing and cardioprotective strategies have been developed to reduce cardiac damage.

- Type II refers to a pattern of often reversible cardiomyopathy with no evidence of acute myocyte injury. This type of cytotoxicity is not dose-dependent. Cardiac damage does not appear to occur in all patients, is expressed in a broad range of severity, and is not associated with identifiable ultrastructural abnormalities. Trastuzumab, a monoclonal antibody, is an example of these agents and may cause a reversible myocyte dysfunction.

Patients undergoing chemotherapy should have careful clinical evaluation and assessment of cardiovascular risk factors and comorbidities before initiating the treatment.

After the treatment beginning, the most frequently used modality for detecting cardiotoxicity is the periodic measurement of left ventricular ejection fraction by 
using echocardiography. Global systolic longitudinal strain assessed by speckle tracking technology has been reported to accurately predict a subsequent decrease in ejection fraction [31]. The use of cardiac biomarkers, in particular troponins, during cardiotoxic chemotherapy, has emerged in the last decade and has proven to be a sensitive and specific tool for early identification and monitoring of anticancer druginduced cardiac injury. Brain natriuretic peptide (BNP) may be useful, but its role in routine surveillance to define high-risk patients is not well established [28, 31].

The timing of cardiotoxicity surveillance, using echocardiography and biomarkers, needs to be personalized to the patients, considering their baseline cardiovascular risk and the specific cancer treatment protocol. Baseline echocardiography is recommended in all patients. Lifelong surveillance should be offered to patients treated with high doses of anthracycline and to survivors of childhood cancer [31].

\subsubsection{Treatment}

If left ventricular ejection fraction decreases $>10 \%$ to a value below the lower limit of normal, ACEi and beta-blockers are recommended [31]. Moreover, when heart failure develops during chemotherapy, it is important to refer the patients to a cardio-oncology specialist and to have a close liaison with the oncology team to determine the necessity and duration of any interruption of cancer treatment [28, 31]. The time from the detection of cardiotoxicity, at the surveillance echocardiography, to the start of heart failure therapy is a crucial variable for recovery of cardiac dysfunction [32]. The historical dogma that anthracycline toxicity is irreversible is mainly due to the fact that the cardiac damage was identified late, while it has been shown that the large majority of patients with left ventricular dysfunction can improve with early therapy [2].

\subsection{Alcoholic Cardiomyopathy}

Alcoholic cardiomyopathy is a form of acquired dilated cardiomyopathy associated with a long history of heavy alcohol abuse (commonly defined as the consumption of over 80-90 g per day over a period of at least 5 years). The disease has a similar prevalence in men and women, although women seem to require a lower total lifetime dose of ethanol to develop symptoms.

Several mechanisms are implicated in mediating the adverse effects of ethanol: oxidative stress, apoptotic cell death, impaired mitochondrial bioenergetics/stress, derangements in fatty acid metabolism and transport, and accelerated protein catabolism [33]. Moreover, genetic factors may predispose to the disease. In a recent study, Ware et al. have shown that truncation variants in the gene encoding titin (TTNtv) represent an important genetic predisposition to alcoholic cardiomyopathy and that the combination of these variants and excess alcohol consumption is associated with worse left ventricular ejection fraction in patients affected by dilated cardiomyopathy [34]. 
Alcoholic cardiomyopathy is characterized by depressed cardiac output, reduced myocardial contractility, and dilatation of all the chambers of the heart. The effect of alcohol on left ventricular function is dose-dependent and progressive, causing, initially, a subclinical diastolic and/or systolic dysfunction, up to the development of low-output dilated cardiomyopathy, leading to episodes of congestive heart failure and even to sudden death [35]. Echocardiography is able to detect subclinical changes in cardiac function, which occur in the early stages of the disease, as abnormal Doppler transmitral flow pattern, indicating impaired left ventricle relaxation; changes in left ventricle volume before the changes in cardiac mass and impairment of diastolic filling may be a sensitive marker of the detrimental effect of alcohol on the heart [36].

Other clinical manifestations of alcoholic cardiomyopathy are arrhythmias. Indeed, chronic alcohol abuse produces multiple physiologic aberrancies in the heart, including ultrastructural changes, effects on the QT interval and heart rate variability, and proarrhythmic electrolyte abnormalities, creating a substrate for triggering nonfatal and fatal arrhythmias [35, 37].

The natural history of alcoholic cardiomyopathy compared with idiopathic dilated cardiomyopathy has been a highly controversial issue [38, 39]. The largest series of patients with alcoholic cardiomyopathy and the earliest to include significant numbers of patients receiving beta-blocker therapy, as well as angiotensinconverting enzyme inhibitor therapy, reported a better prognosis with alcoholic cardiomyopathy than with idiopathic dilated cardiomyopathy [40].

\subsubsection{Treatment}

Complete alcohol withdrawal is usually recommended to all patients with alcoholic cardiomyopathy [41]. Medical therapy is no different from that for other etiologies of heart failure. Moreover, any nutritional deficiencies should be corrected. The use of vitamin supplements is recommended in case of a deficiency, in particular B complex vitamins. Furthermore, it is necessary to correct the electrolyte disturbances, in order to avoid dangerous arrhythmias.

\section{References}

1. Japp AG, Gulati A, Cook SA, Cowie MR, Prasad SK. The diagnosis and evaluation of dilated cardiomyopathy. J Am Coll Cardiol. 2016;67:2996-3010.

2. Bozkurt B, Colvin M, Cook J, Cooper LT, Deswal A, Fonarow GC, et al. Current diagnostic and treatment strategies for specific dilated cardiomyopathies: a scientific statement from the American Heart Association. Circulation. 2016;134:e579-646.

3. Miller BH, Putman CE. The chest radiograph and sarcoidosis. Reevaluation of the chest radiograph in assessing activity of sarcoidosis: a preliminary communication. Sarcoidosis. 1985;2:85-90.

4. Birnie DH, Nery PB, Ha AC, Beanlands RSB. Cardiac sarcoidosis. J Am Coll Cardiol. 2016;68:411-21. 
5. Birnie DH, Sauer WH, Bogun F, Cooper JM, Culver DA, Duvernoy CS, et al. HRS expert consensus statement on the diagnosis and management of arrhythmias associated with cardiac sarcoidosis. Heart Rhythm. 2014;11:1305-24.

6. Wijetunga M, Rockson S. Myocarditis in systemic lupus erythematosus. Am J Med. 2002;113:419-23.

7. Doherty NE, Siegel RJ. Cardiovascular manifestations of systemic lupus erythematosus. Am Heart J. 1985;110:1257-65.

8. Gordon C, Amissah-Arthur M-B, Gayed M, Brown S, Bruce IN, D'Cruz D, et al. The British Society for Rheumatology guideline for the management of systemic lupus erythematosus in adults: executive summary. Rheumatology. 2017;57:14-8.

9. Dhakal BP, Kim CH, Al-Kindi SG, Oliveira GH. Heart failure in systemic lupus erythematosus. Trends Cardiovasc Med. 2018;28:187-97.

10. Myung G, Forbess LJ, Ishimori ML, Chugh S, Wallace D, Weisman MH. Prevalence of resting-ECG abnormalities in systemic lupus erythematosus: a single-center experience. Clin Rheumatol. 2017;36:1311-6.

11. Pérez-Molina JA, Molina I. Chagas disease. Lancet. 2018;391:82-94.

12. Marin-Neto JA, Cunha-Neto E, Maciel BC, Simões MV. Pathogenesis of chronic Chagas heart disease. Circulation. 2007;115:1109-23.

13. de Andrade JP, Marin Neto JA, de Paola AAV, Vilas-Boas F, Oliveira GMM, Bacal F, et al. I Latin American guidelines for the diagnosis and treatment of Chagas' heart disease: executive summary. Arq Bras Cardiol. 2011;96:434-42.

14. Rassi A, Rassi A, Rassi SG. Predictors of mortality in chronic Chagas disease. Circulation. 2007;115:1101-9.

15. Fish AE, Pride YB, Pinto DS. Lyme carditis. Infect Dis Clin North Am. 2008;22:275-88.

16. Lardieri G, Salvi A, Camerini F, Cińco M, Trevisan G. Isolation of Borrelia burgdorferi from myocardium. Lancet. 1993;342:490.

17. Munk PS, Ørn S, Larsen AI. Lyme carditis: persistent local delayed enhancement by cardiac magnetic resonance imaging. Int J Cardiol. 2007;115:2006-8.

18. Feingold B, Mahle WT, Auerbach S, Clemens P, Domenighetti AA, Jefferies JL, et al. Management of cardiac involvement associated with neuromuscular diseases: a scientific statement from the American Heart Association. Circulation. 2017;136:e200-31.

19. Nigro G, Comi LI, Politano L, Bain RJI. The incidence and evolution of cardiomyopathy in Duchenne muscular dystrophy. Int J Cardiol. 1990;26:271-7.

20. Bushby K, Finkel R, Birnkrant DJ, Case LE, Clemens PR, Cripe L, et al. Diagnosis and management of Duchenne muscular dystrophy, part 1: diagnosis, and pharmacological and psychosocial management. Lancet Neurol. 2010;9:77-93.

21. Fayssoil A. Angiotensin-converting enzyme inhibitors and beta-blockers in cardiac asymptomatic patients with Duchenne muscular dystrophy. Indian Heart J. 2010;62:273.

22. Viollet L, Thrush PT, Flanigan KM, Mendell JR, Allen HD. Effects of angiotensin-converting enzyme inhibitors and/or beta blockers on the cardiomyopathy in Duchenne muscular dystrophy. Am J Cardiol. 2012;110:98-102.

23. Jefferies JL, Eidem BW, Belmont JW, Craigen WJ, Ware SM, Fernbach SD, et al. Genetic predictors and remodeling of dilated cardiomyopathy in muscular dystrophy. Circulation. 2005;112:2799-804.

24. Sommerville RB, Vincenti MG, Winborn K, Casey A, Stitziel NO, Connolly AM, et al. Diagnosis and management of adult hereditary cardio-neuromuscular disorders: a model for the multidisciplinary care of complex genetic disorders. Trends Cardiovasc Med. 2017;27:51-8.

25. McNally EM, Sparano D. Mechanisms and management of the heart in myotonic dystrophy. Heart. 2011;97:1094-100.

26. Wahbi K, Babuty D, Probst V, Wissocque L, Labombarda F, Porcher R, et al. Incidence and predictors of sudden death, major conduction defects and sustained ventricular tachyarrhythmias in 1388 patients with myotonic dystrophy type 1. Eur Heart J. 2017;38:751-8.

27. Gulati V, Harikrishnan P, Palaniswamy C, Aronow WS, Jain D, Frishman WH. Cardiac involvement in hemochromatosis. Cardiol Rev. 2014;22:56-68. 
28. Curigliano G, Cardinale D, Suter T, Plataniotis G, De azambuja E, Sandri MT, et al. Cardiovascular toxicity induced by chemotherapy, targeted agents and radiotherapy: ESMO clinical practice guidelines. Ann Oncol. 2012;23:vii155-66.

29. Zhang S, Liu X, Bawa-Khalfe T, Lu L-S, Lyu YL, Liu LF, et al. Identification of the molecular basis of doxorubicin-induced cardiotoxicity. Nat Med. 2012;18:1639-42.

30. Felker GM, Thompson RE, Hare JM, Hruban RH, Clemetson DE, Howard DL, et al. Underlying causes and long-term survival in patients with initially unexplained cardiomyopathy. N Engl J Med. 2000;342:1077-84.

31. Zamorano JL, Lancellotti P, Rodriguez Muñoz D, Aboyans V, Asteggiano R, Galderisi M, et al. 2016 European Society of Cardiology position paper on cancer treatments and cardiovascular toxicity. Eur Heart J. 2016;37:2768-801.

32. Cardinale D, Colombo A, Bacchiani G, Tedeschi I, Meroni CA, Veglia F, et al. Early detection of anthracycline cardiotoxicity and improvement with heart failure therapy. Circulation. 2015;131:1981-8.

33. Piano MR, Phillips SA. Alcoholic cardiomyopathy: pathophysiologic insights. Cardiovasc Toxicol. 2014;14:291-308.

34. Ware JS, Amor-salamanca A, Tayal U, Govind R, Serrano I, Pascual-figal DA, et al. Genetic etiology for alcohol-induced cardiac toxicity. J Am Coll Cardiol. 2018;71:2293-302.

35. Fernández-Solà J. Cardiovascular risks and benefits of moderate and heavy alcohol consumption. Nat Rev Cardiol. 2015;12:576-87.

36. Lazarević AM, Nakatani S, Nešković AN, Marinković J, Yasumura Y, Stojičić D, et al. Early changes in left ventricular function in chronic asymptomatic alcoholics: relation to the duration of heavy drinking. J Am Coll Cardiol. 2000;35:1599-606.

37. George A, Figueredo VM. Alcohol and arrhythmias: a comprehensive review. J Cardiovasc Med. 2010;11:221-8.

38. Fauchier L, Babuty D, Poret P, Casset-Senon D, Autret ML, Cosnay P, et al. Comparison of long-term outcome of alcoholic and idiopathic dilated cardiomyopathy. Eur Heart J. 2000;21:306-14.

39. Prazak P, Pfisterer M, Osswald S, Buser P, Burkart F. Differences of disease progression in congestive heart failure due to alcoholic as compared to idiopathic dilated cardiomyopathy. Eur Heart J. 1996;17:251-7.

40. Guzzo-Merello G, Segovia J, Dominguez F, Cobo-Marcos M, Gomez-Bueno M, Avellana P, et al. Natural history and prognostic factors in alcoholic cardiomyopathy. JACC Heart Fail. 2015;3:78-86.

41. Guzzo-Merello G, Cobo-Marcos M, Gallego-Delgado M, Garcia-Pavia P. Alcoholic cardiomyopathy. World J Cardiol. 2014;6:771-81.

Open Access This chapter is licensed under the terms of the Creative Commons Attribution 4.0 International License (http://creativecommons.org/licenses/by/4.0/), which permits use, sharing, adaptation, distribution and reproduction in any medium or format, as long as you give appropriate credit to the original author(s) and the source, provide a link to the Creative Commons license and indicate if changes were made.

The images or other third party material in this chapter are included in the chapter's Creative Commons license, unless indicated otherwise in a credit line to the material. If material is not included in the chapter's Creative Commons license and your intended use is not permitted by statutory regulation or exceeds the permitted use, you will need to obtain permission directly from the copyright holder. 